\title{
Growth and characterization of indium antimonide and gallium antimonide crystals
}

\author{
N K UDAYASHANKAR* and H L BHAT ${ }^{\dagger}$ \\ Department of Physics, Karnataka Regional Engineering College, Surathkal, Srinivasnagar 574 157, India \\ †Department of Physics, Indian Institute of Science, Bangalore 560 012, India
}

MS received 4 January 2001; revised 22 June 2001

\begin{abstract}
Indium antimonide and gallium antimonide were synthesized from the respective component elements using an indigenously fabricated synthesis unit. Bulk crystals of indium antimonide and gallium antimonide were grown using both the vertical and horizontal Bridgman techniques. Effect of ampoule shapes and diameters on the crystallinity and homogeneity was studied. The grown crystals were characterized using X-ray analysis, EDAX, chemical etching, Hall effect and conductivity measurements. In the case of gallium antimonide, effect of dopants (Te and In) on transport and photoluminescence properties was investigated.
\end{abstract}

Keywords. Synthesis; crystallization; chemical etching; defect density; Hall measurements; photoluminescence (PL) spectra.

\section{Introduction}

Among the III-V binary semiconductors, indium antimonide (InSb) has attracted considerable attention over the last several years. Many of its interesting properties are directly associated with its very low effective electron mass and high mobilities. Consequently, it is an important candidate in high speed applications in transistors and other devices (van Welzenis and Ridley 1984; Egan et al 1994). It has the smallest bandgap among other III-V binaries, measuring $0.17 \mathrm{eV}$ at $300 \mathrm{~K}$ that corresponds to IR wavelength $(6 \cdot 2 \mu \mathrm{m})$ and the material is therefore useful as an infrared detector and filter. New materials like InTlSb (van Schilfgaarde et al 1993) have also opened up further possibility of their utilization in long wavelength IR region. However, the use of InSb in such devices requires a large diameter single crystal having homogeneous impurity distribution and low dislocation density to ensure optimum performance with high yield and good reliability. Similarly, from the device point of view, gallium antimonide $(\mathrm{GaSb})$ based structures have shown potentiality for applications in laser diodes with low threshold, photodetectors, super lattices with tailored optical and transport characteristics (Nagao et al 1981; Munekata et al 1986; Santos et al 1988; Xie et al 1991). In fact, $\mathrm{GaSb}$ is found to be a useful substrate material because its lattice parameter matches with the solid solutions of various ternary and quaternary III-V compounds covering bandgaps over a wide spectral range from $\sim 0.3$

*Author for correspondence
(InGaAsSb) to $1.58 \mathrm{eV}$ (AlGaSb), i.e. 0.8-4.3 $\mu \mathrm{m}$ (Milnes and Polyakov 1993). Consequently, GaSb based binary and ternary alloys have turned out to be important candidates for applications in longer wavelength lasers and photodetectors for fibre optic communication (Capasso et al 1980). These have stimulated a lot of interest in $\mathrm{GaSb}$ for basic research as well as device fabrication (Segawa et al 1976; Motosugi and Kagawa 1980; Hildebrand et al 1981). Although GaSb crystals are widely grown by Czochralski method (Moravec 1993), there are a few reports on the growth of $\mathrm{GaSb}$ using other melt techniques, viz. vertical gradient freeze technique (Jamieson 1963), travelling heater method (Benz and Muller 1979; Muller and Neumann 1983), Bridgman technique (Harsy et al 1981; Roy and Basu 1990), etc.

A large number of growth techniques have been employed in the past for preparing a variety of Sb-based compounds. However, the dopant striations, twinning, grain boundaries and other phenomena which degrade the wafer quality are reported throughout the literature (e.g. Antonov et al 1983; Buzynin et al 1988; Brezina and Fousek 1989; Hayakawa et al 1990; Helmer et al 1995; Kozhemyakin 1995), the causes of which are not accounted for in sufficient details. Particularly, Bridgman technique is beset with the problems related to polycrystallinity and structural defects induced by the crucible walls. The incorporation of stress in the lattice due to differential thermal expansion of the crucible and the growing ingot is deleterious to device performance. The structural quality, crystallinity, impurity distribution etc in crystals grown by directional solidification are generally controlled by temperature gradients and growth ambients 
around the growing crystal. This seems to be very challenging and arduous, particularly in the growth of such compound semiconductors.

In this paper we present some of our results concerning the synthesis and crystal growth of indium antimonide and gallium antimonide compounds from their respective component elements. To carry out the synthesis of InSb and $\mathrm{GaSb}$, a suitable mixing furnace was designed and fabricated. It was then integrated into a home-made synthesis unit. The growth experiments were carried out using both vertical and horizontal Bridgman techniques. In particular, for horizontal Bridgman growth experiments, a suitable high temperature growth furnace was also designed and then integrated into an indigenously built growth unit. However, vertical Bridgman growth experiments were carried out using a commercial BCG (UK) crystal growth apparatus. In addition to the development and modification of synthesis and growth units to suit the material preparation of indium antimonide and gallium antimonide, some of the results on preliminary characterization on these crystals are also presented here.

\section{Experimental}

\subsection{Materials synthesis}

Most of the techniques that have been developed for preparing pure single crystals of germanium or silicon can also be applied to the III-V compounds. But in the preparation of these compounds there are often difficulties which arise from the presence of two elements. Indium antimonide and gallium antimonide were synthesized starting from their respective high purity elements taken in appropriate quantities for which a synthesizing unit was developed with a mixing furnace. The mixing furnace is a horizontal cylindrical furnace with a $45 \mathrm{~mm}$ ID, $50 \mathrm{~mm}$ long muffle wound with nichrome wire. The furnace can be powered to 250 watts to reach temperatures as high as $\sim 850^{\circ} \mathrm{C}$ to give $8 \mathrm{~cm}$ long isothermal region. The furnace temperature is controlled through a Heatcon India 'on/off' controller having an accuracy of $\pm 1{ }^{\circ} \mathrm{C}$. A stainless steel tube of $25 \mathrm{~mm}$ ID, $28 \mathrm{~mm}$ OD and $64 \mathrm{~cm}$ long coaxial to the furnace muffle is supported by bearings on both sides. The quartz ampoule filled with the starting elements is placed horizontally inside this tube. The steel tube has the capability of periodic rotation both in clockwise and anticlockwise directions at a rate of 9 rotations per minute facilitating proper mixing of the molten elements to form the compound.

Synthesis of InSb involves the preparation of homogenized sample of InSb from elemental In and $\mathrm{Sb}$. The ratio of In atoms to $\mathrm{Sb}$ atoms in the homogenized sample should be $1: 1$. Since the atomic weights of In and $\mathrm{Sb}$ are 114.82 and $121.75 \mathrm{amu}$ respectively, the ratio by weight should be $1: 1.06$. In the case of GaSb, since the atomic weights of $\mathrm{Ga}$ and $\mathrm{Sb}$ are 69.72 and $121.75 \mathrm{amu}$ respec- tively, the ratio by weight should be $1: 1 \cdot 75$. Required quantities of tellurium were also added to synthesize Te-doped GaSb. The starting elements used for the synthesis of InSb and $\mathrm{GaSb}$ were of $5 \mathrm{~N}$ purity. Initially, before weighing, elemental In was etched with $\mathrm{HNO}_{3}$, Ga with hot $\mathrm{HCl}$ and $\mathrm{Sb}$ with aqua regia for the removal of their surface oxides. Then chemically cleaned semiconductor grade (GE214) silica tube of $16 \mathrm{~mm}$ bore and $8 \mathrm{~cm}$ in length with a round bottom filled with the required starting elements (In and $\mathrm{Sb}$ in the case of $\mathrm{InSb}$ ) was sealed under dynamic vacuum of $\sim 3 \times 10^{-6}$ Torr. The filled ampoule was then loaded into the synthesizing unit and mixing was carried out for $24 \mathrm{~h}$. The synthesized material was removed from the ampoule after cooling the furnace gradually to room temperature. Occasionally, high temperature pre-synthesis baking at high vacuum $\left(10^{-6}\right.$ Torr) was found quite effective in getting rid off volatile oxide impurities. Generally, the starting material for a few growth runs were synthesized together which helped to eliminate batch to batch variation in stoichiometry. Extreme care was taken in the transfer of material to maintain the accuracy to the level of $\mu \mathrm{g} / \mathrm{g}$ of material.

\subsection{Crystal growth}

2.2a Vertical Bridgman growth: The crystal growth of $\mathrm{InSb}$ and $\mathrm{GaSb}$ was carried out using a Metal Research BCG (UK) 365 growth unit in a vertical Bridgman configuration. A schematic diagram of the furnace and the crucible system is shown in figure 1. The charge was melted by a single zone tubular resistive heater, $21 \mathrm{~cm}$ long with a bore dimension of $2.5 \mathrm{~cm}$. The growth chamber was evacuated to $10^{-3}$ Torr throughout the experiment in order to avoid connective losses and to reduce convection driven instabilities. The temperature environment is controlled with an accuracy of $\pm 0 \cdot 1^{\circ} \mathrm{C}$ by a Eurotherm proportional band controller configured to the system. The thermal profiling of the furnace is precisely mapped (figure 2) and gradients in the range from 10 to $80^{\circ} \mathrm{C} / \mathrm{cm}$ (figure 3) at the melting point of the above materials could be invoked by varying the input power to the furnace. The ampoule could be lowered through the chosen gradient temperature profile of the furnace with selected translational rates in the range $1 \mathrm{~mm} / \mathrm{h}$ to $25 \mathrm{~mm} / \mathrm{h}$. The synthesized $\mathrm{InSb}$ (or GaSb) was removed from the round bottom quartz ampoule and then subjected to proper chemical cleaning and then filled in $10 \mathrm{~mm}$ bore and $12 \mathrm{~cm}$ long silica ampoule drawn from semiconductor grade GE214 tube. The ampoule was provided with a proper conical tip at the bottom to facilitate nucleation for single crystal growth. The filled ampoule was then sealed under dynamic vacuum of $\sim 10^{-6}$ Torr. The sealed ampoule was then loaded into the growth unit and furnace temperature was increased to $750^{\circ} \mathrm{C}$ (a typical run) and the melt was homogenized for $3 \mathrm{~h}$. The growth was 
carried out at different experimental conditions. The temperature gradient employed was in the range $50-60^{\circ} \mathrm{C} / \mathrm{cm}$ whereas lowering rates selected were in the range 1.5$2.5 \mathrm{~mm} / \mathrm{h}$. Even after solidification, the lowering rate was maintained at the same rate till the entire ampoule was out of the furnace so as to obtain an effective annealing of the crystal which would eventually decrease the dislocation density. The ingot was taken out by carefully cutting open the quartz ampoule. The ingots of $4-5 \mathrm{~cm}$ long and $10 \mathrm{~mm}$ in diameter could be routinely grown (figures $4 \mathrm{a}$ and b). Monocrystalline boules were easily cleaved parallel to $\{110\}$ cleavage planes. Occasionally, though ingots were solid and free from any inclusions, the surface contained semi-spherical depressions of 1-2 mm diameter due to air enclosed between the ampoule wall and the molten alloy. However, the wafers could be obtained from the uniform region of even such ingots.

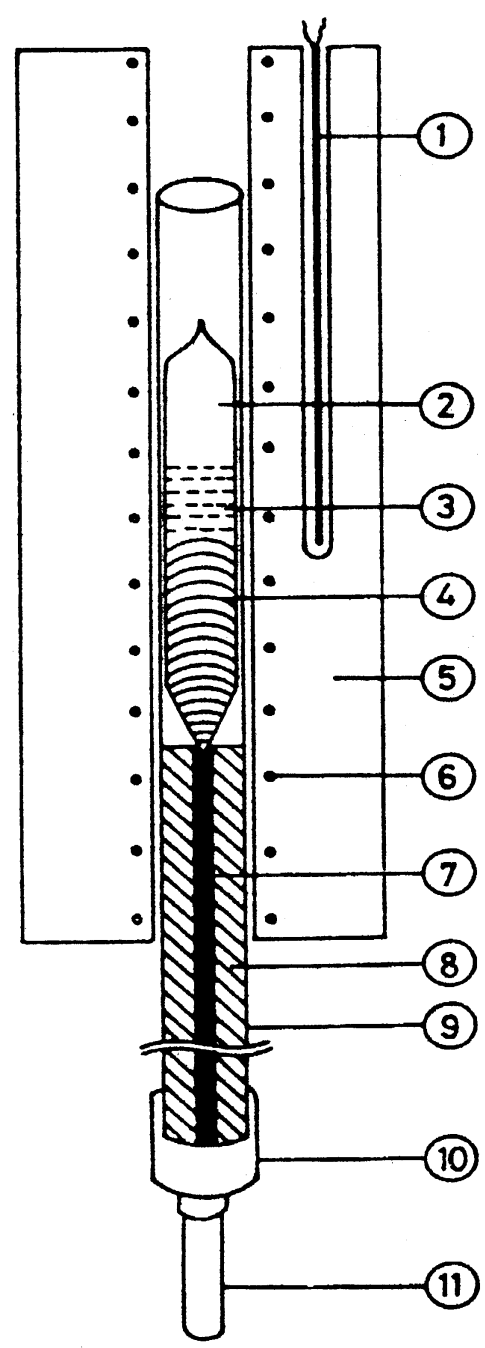

Figure 1. Vertical Bridgman furnace and crucible assembly: 1. $\mathrm{NiCr} / \mathrm{NiAl}$ control thermocouple, 2. quartz ampoule, 3. melt, 4. crystal, 5. furnace, 6. furnace element, 7. ampoule stem, 8. quartz wool, 9. quartz crucible holder, 10. stainless steel coupler and 11. stainless steel lowering rod. 2.2b Horizontal Bridgman growth: Horizontal Bridgman growth unit consists of a single zone growth furnace through which a one meter long silica tubing with a bore of $20 \mathrm{~mm}$ passes coaxially. The quartz ampoule filled with the charge is placed horizontally inside this tube. The travel speed of the furnace is selected by coupling the lead screw to a turret type commercial geared motor capable of angular speeds from $0 \cdot 00082888$ to $10 \cdot 35 \mathrm{rpm}$ with 20 intermediate steps in between. The fabricated furnace, coaxial to the silica tube has a bore of $31 \mathrm{~mm}$ and is capable of maintaining temperatures up to $\sim 1000^{\circ} \mathrm{C}$ at its centre. The furnace temperature is monitored using PID (Century Systems) temperature controller/recorder which is compatible with a Type-K chromel-alumel thermocouple. Typical temperature profiles of the furnace is

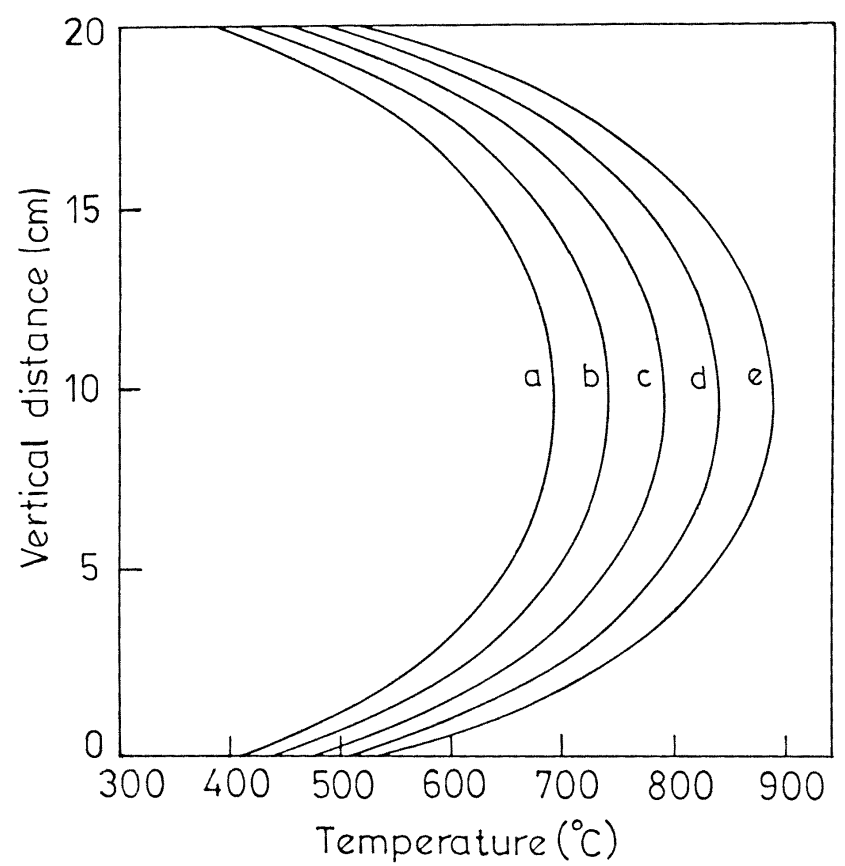

Figure 2. Temperature profiles of vertical Bridgman furnace.

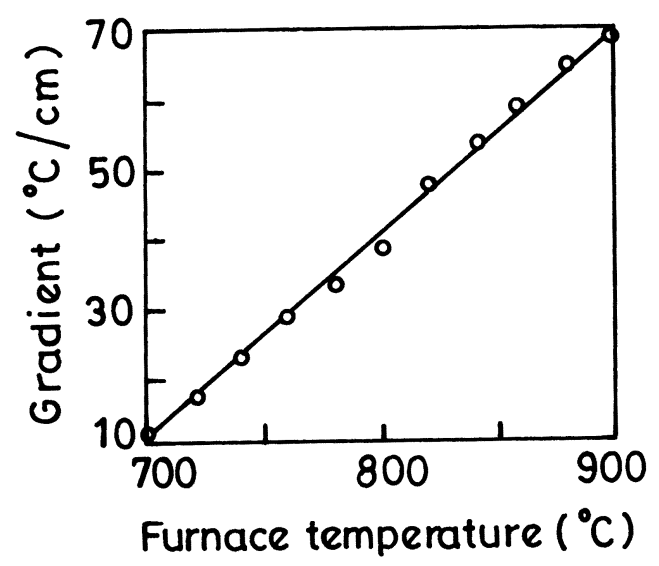

Figure 3. Gradient vs maximum furnace temperature. 
shown in figure 5. For the growth of single crystals of indium antimonide using horizontal Bridgman technique, the chemically synthesized InSb polycrystalline material was transferred to a quartz ampoule having a conical tapering and then evacuated $\left(\sim 10^{-6}\right.$ Torr) and sealed. The ampoule was then loaded into the horizontal Bridgman unit and given a small inclination of about $10^{\circ}$ to ensure proper filling of the conical tip. The furnace temperature was increased to $750^{\circ} \mathrm{C}$ and homogenized for $3 \mathrm{~h}$. The temperature gradients in the range $35-85^{\circ} \mathrm{C} / \mathrm{cm}$ and furnace travel rates in the range $1-5 \mathrm{~mm} / \mathrm{h}$ were employed for the growth. In this way, the crystals with length 5$6 \mathrm{~cm}$ with a maximum diameter of $\sim 10 \mathrm{~mm}$ were grown. Typical crystals grown by this method can be seen in figures $6 a$ and $b$.

\section{Characterization}

For the purpose of electrical measurements, wafers of $\sim 1 \mathrm{~mm}$ were sliced parallel to $\{110\}$ cleavage planes from the grown ingots of InSb and GaSb using a Buehler Isomet low speed saw and then subjected to lapping using $\mathrm{SiC}$ wet paste. Then they were polished with $5 \mu \mathrm{m}$ grade wet alumina oxide paste and then with Buehler micropolish $(0.3 \mu \mathrm{m}$ Alpha alumina/Linde alumina). Samples
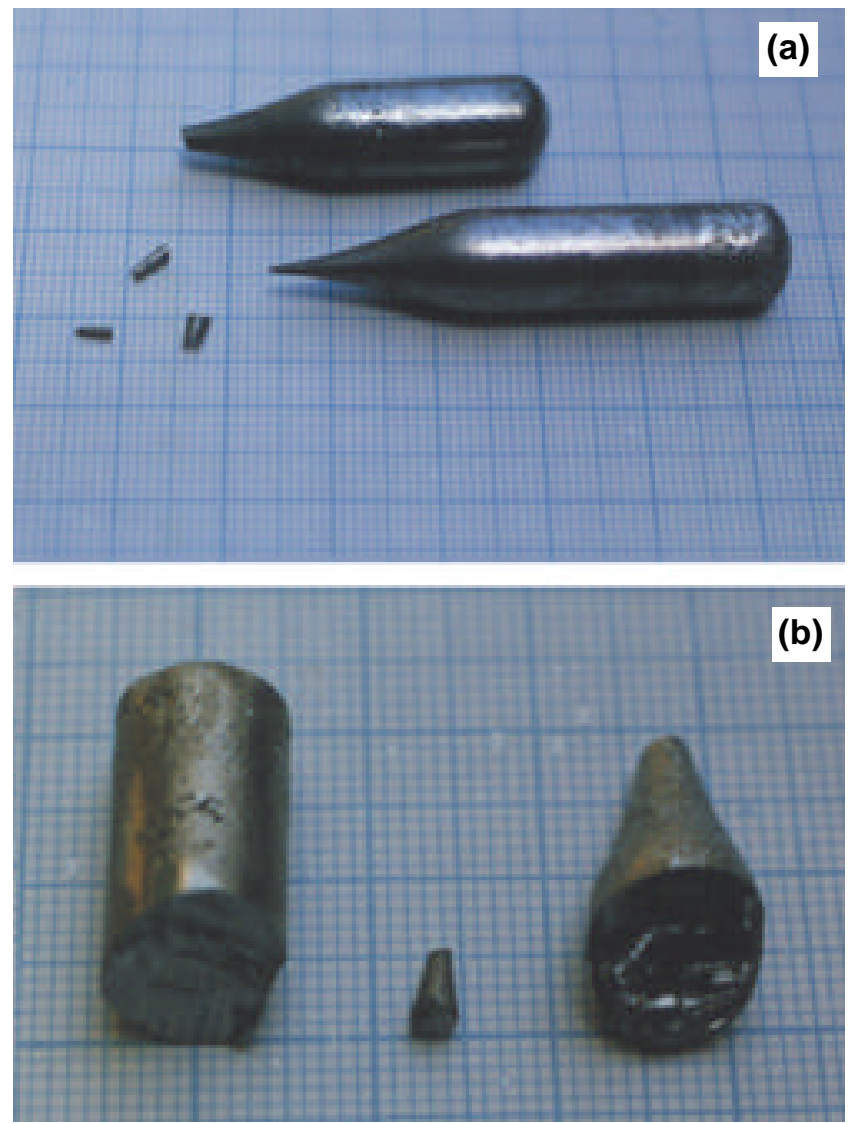

Figure 4. Crystals grown by vertical Bridgman method (a) $\mathrm{InSb}$ and (b) GaSb. were degreased for $2 \mathrm{~min}$ in boiling trichloro-ethylene, rinsed by ultrasonic vibration in acetone and methanol and then chemically etched in a mixture of $\mathrm{HCl}$ and water to remove any oxide. Rinsing in deionized water and exposing to the air were avoided in order to minimize the oxide formation. The wafers were then stored in methanol for use. In fact, the single crystal wafers $\{110\}$ obtained from InSb (figure 7) grown by both these techniques were used as substrates for growing thin films using liquid phase epitaxy and results have been published elsewhere.

Further, the chemical etching was carried out to study the surface morphology and defect density of these crystals. To reveal the grain boundaries and dislocation etch pits in InSb and $\mathrm{GaSb}$, selective chemical etchants viz. $\mathrm{HNO}_{3}$ : $\mathrm{HF}: \mathrm{CH}_{3} \mathrm{COOH}: \mathrm{H}_{2} \mathrm{O}(10: 5: 2: 5)$ and $\mathrm{HNO}_{3}$ : $\mathrm{HF}: \mathrm{CH}_{3} \mathrm{COOH}: \mathrm{H}_{2} \mathrm{O}(1: 1: 2: 5)$ were used respectively. The Hall concentration and the resistivity were measured using van der Pauw geometry to within $\pm 5 \%$ accuracy. For optical characterization, low temperature photoluminescence (PL) spectra were taken for undoped and Te-doped GaSb samples. Prior to PL measurements, the wafers were degreased sequentially in trichloroethelene, acetone and methanol and then chemically etched in $\mathrm{HCl}: \mathrm{H}_{2} \mathrm{O}(1: 1)$ to remove any oxide. The PL measurements were carried out using a MIDAC Fourier transform photoluminescence spectrometer. A resolution of $0.5 \mathrm{meV}$ was used in our measurements.

\section{Results and discussion}

\subsection{Stoichiometry and homogeneity}

The powder XRD analysis confirmed the synthesis of indium antimonide with prominent peaks from

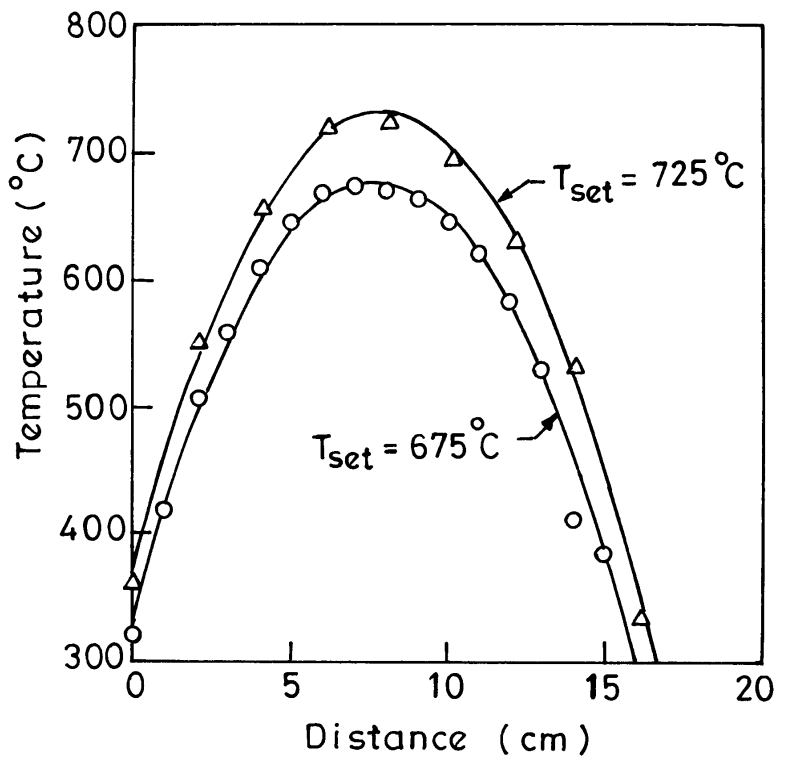

Figure 5. Temperature profiles of the horizontal Bridgman furnace. 

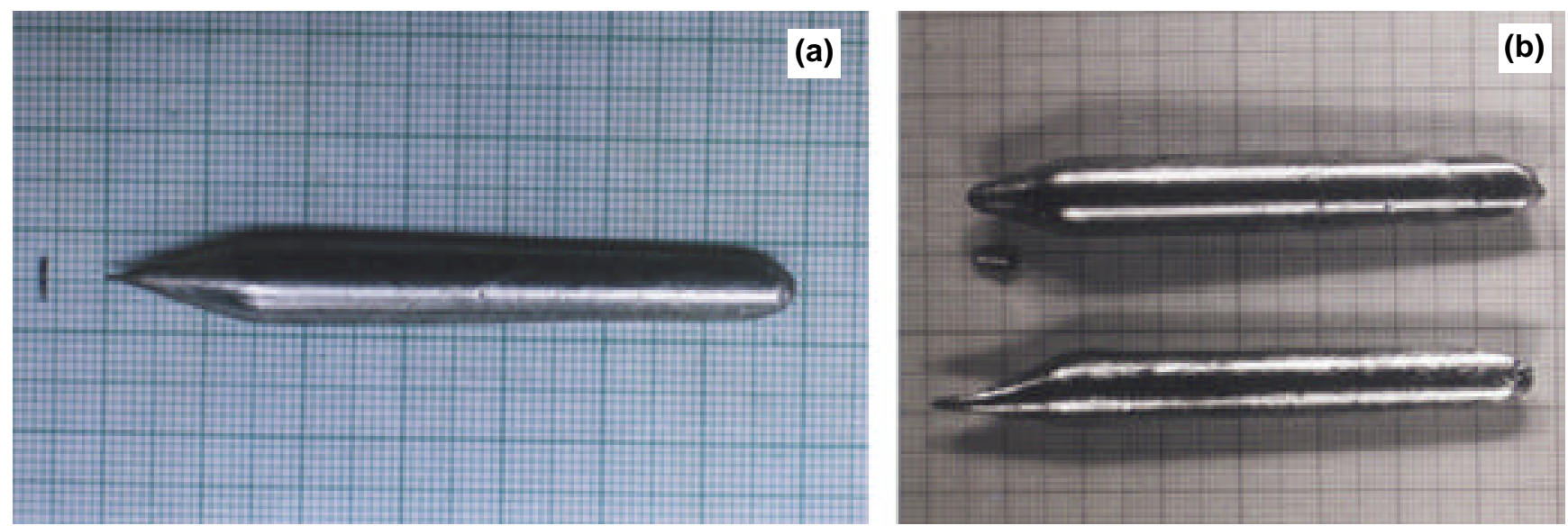

Figure 6. Crystals grown by horizontal Bridgman method a. InSb and b. GaSb.

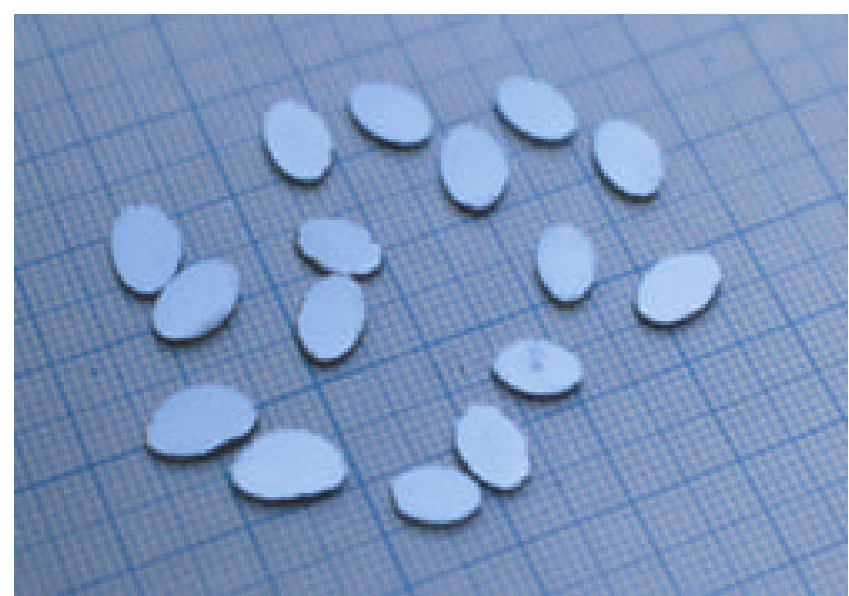

Figure 7. InSb wafers.

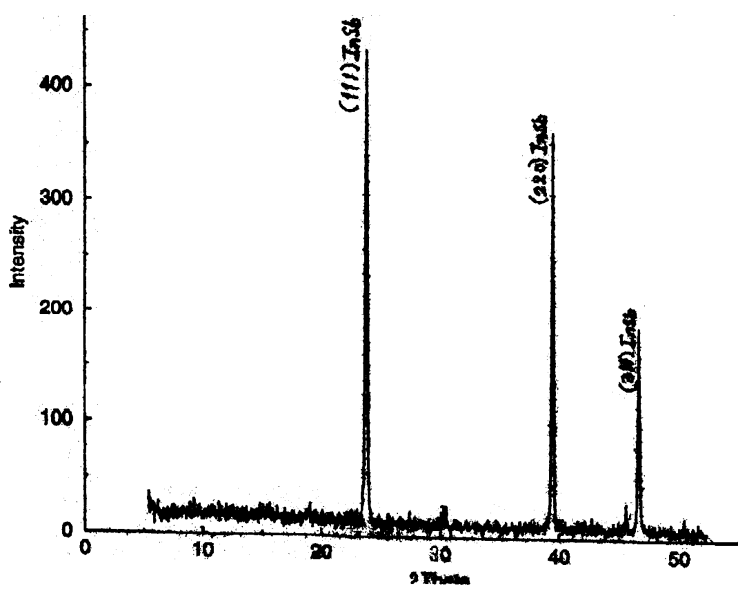

Figure 8. XRD spectrum of InSb.

(111), (220) and (311) planes (see figure 8). The lattice constant was evaluated to be $6.29 \AA$ at room temperature, employing $\mathrm{CoK}_{\alpha}$ radiation $[\lambda=1.7902 \AA$ The

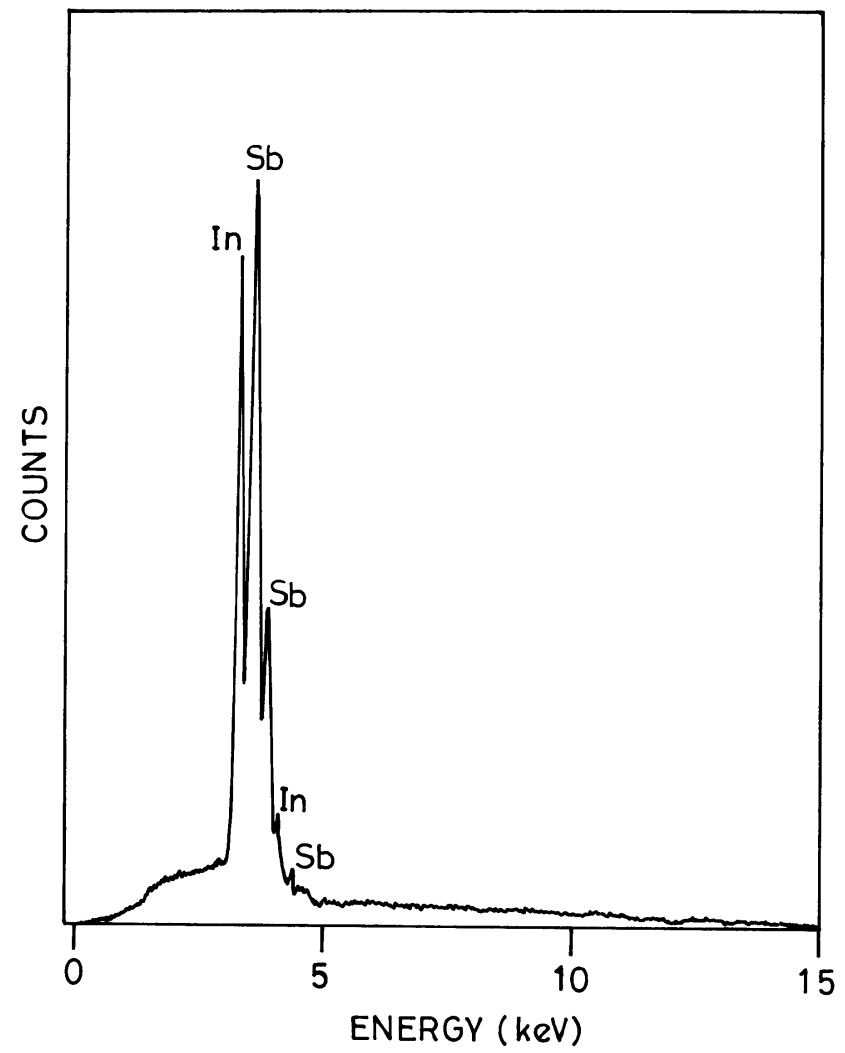

Figure 9. EDAX spectrum of InSb.

typical EDAX spectrum is also shown in figure 9. The analysis confirmed the stoichiometry of the synthesized InSb with In : Sb ratio of 50.3:49.7 (at\%). Similarly, from the corresponding EDAX spectrum of $\mathrm{GaSb}$ (figure 10 ), the $\mathrm{Ga} / \mathrm{Sb}$ ratio (at\%) was found to be 0.99 . In both these cases, it was observed that $\mathrm{In} / \mathrm{Sb}$ (or $\mathrm{Ga} / \mathrm{Sb}$ ) ratio was found to increase slightly from the tip to the upper end of the ingot. This is mainly because of the antimony loss due to volatilization during growth. 


\subsection{Effect of ampoule shape}

The use of appropriate shape of the ampoule is important in the case of Bridgman technique so as to produce a single nucleus which would then propagate to form just one crystal from the whole charge. The formation of just one nucleus is more probable if the super-cooled volume is small. The ampoules with conical shapes greatly enhance this probability. In fact, the conical tip in the ampoule is the point of initiation of the solidification and controls further growth. The ampoule shapes used in the present vertical Bridgman growth experiments are shown in figure 11.

The grain selection that promotes the growth of one grain at the expense of others leading to the single crystal growth could be best observed with the shape shown in figure 11c. But, the main disadvantage of this particular configuration is the cracking at the constricted portion at the bottom which is quite common with these ampoules. Hence in most of the experiments ampoule tips shown in figure $11 \mathrm{a}$ or $11 \mathrm{~b}$ were used. Two distinct shapes used in horizontal Bridgman growth experiments were (i) conical and (ii) semi-conical (figure 12). The ampoule with conical shape shown in figure $12 \mathrm{a}$ was found to be disadvantageous. This was because of the fact that the molten charge did not properly fill right from the tip of the ampoule when placed horizontally which could be required for single crystal growth. However, the ampoule filled with the synthesized material could be vertically placed in a separate melting furnace and the molten charge could be given necessary jerks so that the material filled right from

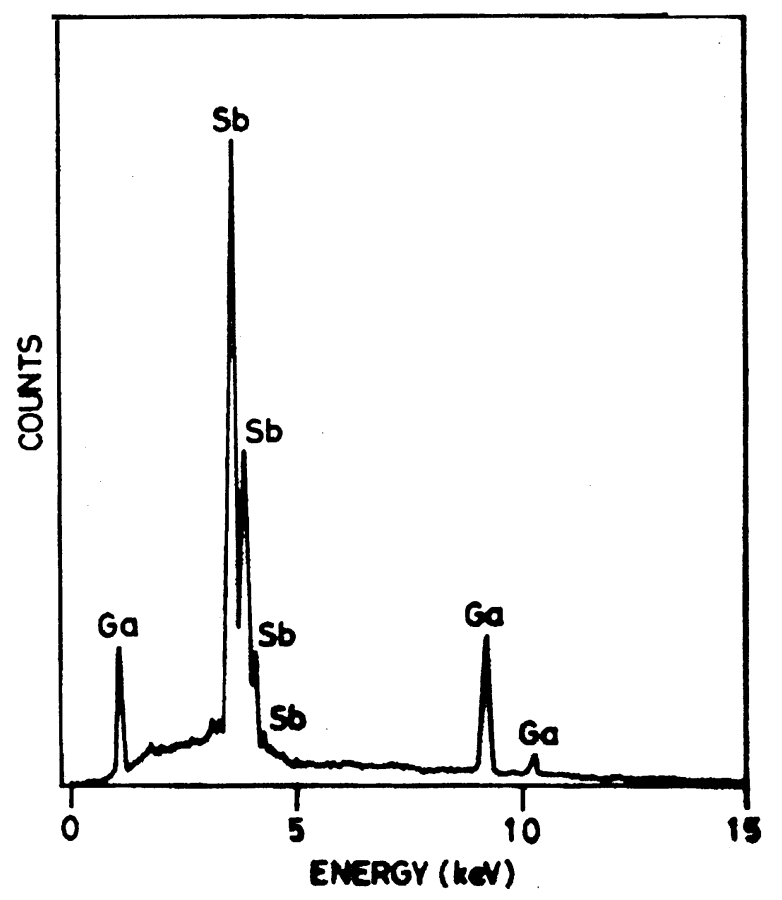

Figure 10. EDAX spectrum of GaSb. the tip of the ampoule and then solidified slowly to room temperature by placing it with slight inclination. This ampoule containing the solidified charge was used for succeeding growth experiments. On the other hand, ampoule with the shape shown in figure $12 \mathrm{~b}$ was most conveniently used in the experiments. In this case, the tip of the ampoule was always filled and no small angle inclination was required to carry out the growth. In fact, typical GaSb crystals grown using these two shapes are shown in figure $6 \mathrm{~b}$. In general, it was found that in wider ampoule of $10 \mathrm{~mm}$ diameter the ingots of better quality could be grown even at slightly larger lowering rates $(\sim 2.5 \mathrm{~mm} / \mathrm{h})$. The decrease of lowering rate promotes the formation of larger crystals due to uniform heat conduction. However, its effect was more noticeable in the case of $10 \mathrm{~mm}$ ampoules as compared to $8 \mathrm{~mm}$ ampoules. In general, the narrow ampoules of diameters less than $8 \mathrm{~mm}$ tend to result in polycrystallinity. It may be noted that for larger ampoule diameters, non-uniform heat conduction results in polycrystallinity and for small diameters, the wall effect is responsible for polycrystallinity as suggested by Harsy et al (1981).

\subsection{Transport properties}

As grown indium antimonide crystals were found to be $n$-type as determined by the hot probe technique. From

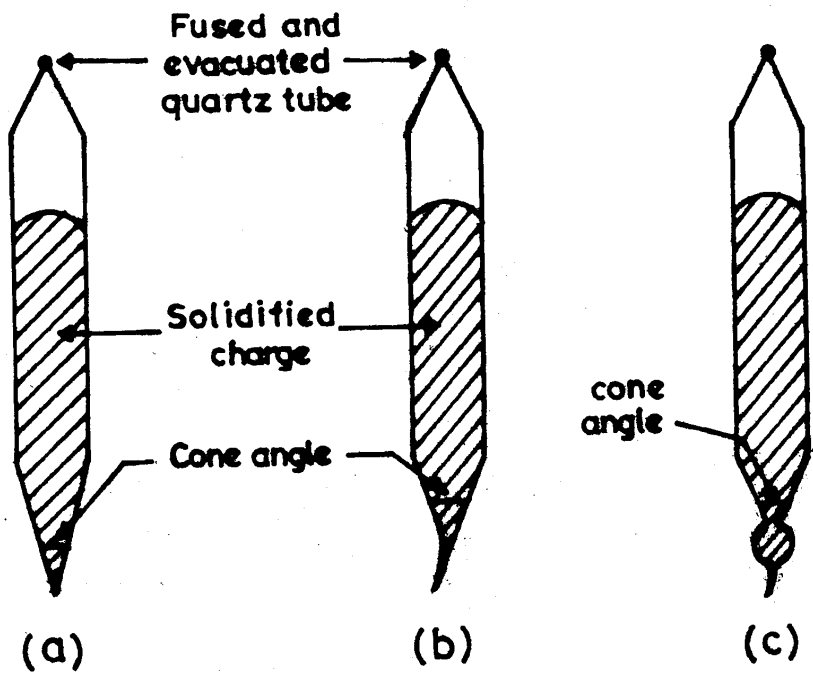

Figure 11. Ampoule shapes used in vertical Bridgman experiments.

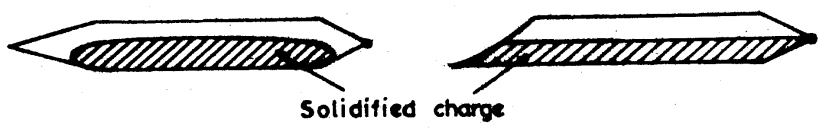

(a)

(b)

Figure 12. Ampoule shapes used in horizontal Bridgman experiments. 
Hall measurements, the following data were obtained: room temperature mobility was found to be $1.2 \times$ $10^{5} \mathrm{~cm}^{2} / \mathrm{Vs}$ which remained approximately constant throughout the crystal. The fact that the mobility must be large can be appreciated qualitatively from the small electron effective mass, $m_{\mathrm{n}}=(0.013 \pm 0.001) m_{\mathrm{o}}$ obtained from the cyclotron experiments (Dresselhaus et al 1955). The observed mobility has increased steadily with improvement in the purity of the material. For a sample with donor concentration of $8 \times 10^{12} \mathrm{~cm}^{-3}$ an electron mobility of $1.1 \times 10^{6} \mathrm{~cm}^{2} / \mathrm{Vs}$ was measured by Grandsen (1958). However, Keys (1954) had reported a still higher value of about $10^{7} \mathrm{~cm}^{2} / \mathrm{Vs}$ for a pure sample of $\mathrm{InSb}$ at room temperature. The measured carrier concentration for our samples was of the order of $10^{16} \mathrm{~cm}^{-3}$. The room temperature resistivity varied between 0.046 and $0.058 \Omega \mathrm{cm}$. The mobility and carrier concentration at $77 \mathrm{~K}$ were determined to be $2.4 \times 10^{5} \mathrm{~cm}^{2} / \mathrm{Vs}$ and $2.2 \times 10^{15} \mathrm{~cm}^{-3}$, respectively. It may be noted that narrow bandgap energy implies a large intrinsic carrier concentration at room temperature. Hence, it follows that the material of reasonable purity $\left(\sim 10^{15}\right.$ impurities) is in the intrinsic range even at room temperature (Hrostowski et al 1955).

As grown gallium antimonide crystals were found to be $p$-type as determined by the hot probe technique. It may be noted that the first investigations on $\mathrm{GaSb}$ were made on undoped $p$-type material. All methods of preparation used so far for GaSb result in material with a residual acceptor concentration of $10^{17} \mathrm{~cm}^{-3}$. Undoped material is therefore generally $p$-type unless intentional doping is carried out to bring about strong compensation of acceptors originating in native defects. However, transport in $n$-type $\mathrm{GaSb}$ is complicated by the contribution of three sets of conduction bands with minima situated at $\Gamma, L$ and $X$. Data on transport coefficients can be consistently explained by a three-band model, X-bands contributing to transport above $180^{\circ} \mathrm{C}$ (Lee and Woolley 1981). A list of mobility values reported in literature is shown in table 1. From Hall measurements, the following data were obtained for our samples : for undoped as grown $p$-type samples, the room temperature average mobility was found to be $712.4 \mathrm{~cm}^{2} / \mathrm{Vs}$ which remained approximately constant throughout the crystal. The measured carrier concentration for our samples was of the order of $10^{17} \mathrm{~cm}^{-3}$. The room temperature resistivity varied between 0.046 and $0.058 \Omega \mathrm{cm}$.

\subsection{Dopant effect}

One of the shortcomings of GaSb is its high level of concentration of residual acceptors (Etter and Etter 1964; van Maaren 1966) leading to very low resistivity $\left(\sim 10^{-2} \Omega \cdot \mathrm{cm}\right)$. The concentration is as high as $\sim 10^{17} \mathrm{~cm}^{-3}$ (Stepanek and Sestakova 1992) and the acceptor was identified as the vacancy complex $\mathrm{V}_{\mathrm{Ga}} \mathrm{Ga}_{\mathrm{Sb}}$ (Kaiser and Fan 1965; van der Meulen 1964). The epitaxial technology needs to use the substrate wafers with a low free carrier density $\left(<10^{14} \mathrm{~cm}^{-3}\right)$ and/or high resistivity $\left(\sim 10^{7} \Omega \cdot \mathrm{cm}\right)$. In order to prepare such samples the method of compensation of the residual acceptors using proper doping $\left(10^{19}\right.$ atoms $\left./ \mathrm{cm}^{3}\right)$ of the bulk crystals was employed. In the present investigation, indium and tellurium were used as dopants for studying their influence on transport properties of the grown crystal. The resistivity was found to be more for a sample from the uniform zone near the tip as compared to the one near the dome of the grown ingot. The carrier concentration was found to increase from the tip to the dome. This could be explained on the basis of the fact that impurities segregated towards the dome region during lowering of the ampoule for growing the crystal. The average values of carrier concentration, mobility and resistivity are given in table 2 .

\subsection{Etch pit density measurements}

During the course of this work some of the main problems encountered were the post-growth extraction of the crystals, inhomogeneity and the large dislocation density and so on. Quite often post-growth extraction from the silica ampoule was rendered difficult due to sticking of the material to inner surfaces of the ampoule. Therefore a

Table 1. List of mobility values of GaSb reported in literature.

\begin{tabular}{lcccl}
\hline Type of dopant & $\begin{array}{c}\text { Conductivity } \\
\text { type }\end{array}$ & $\begin{array}{c}\text { Carrier concentration } \\
\left(\mathrm{cm}^{-3}\right)\end{array}$ & $\begin{array}{c}\text { Mobility } \\
\left(\mathrm{cm}^{2} / \mathrm{Vs}\right) \\
(300 \mathrm{~K})\end{array}$ & \multicolumn{1}{c}{ Reference } \\
\hline Undoped & $p$ & $10^{17}$ & 1420 & Edwards et al $(1959)$ \\
Undoped & $p$ & $1 \cdot 08 \times 10^{17}$ & 742 & Cockayne et al $(1982)$ \\
Undoped & $p$ & $10^{17}$ & 680 & Heller and Hamerly (1985) \\
Undoped & $p$ & $(2 \cdot 36-2 \cdot 78) \times 10^{17}$ & $417-440$ & Roy and Basu (1990) \\
Te-doped & $n$ & $5 \times 10^{17}$ & 2217 & Roy and Basu (1990) \\
S-doped & $n$ & $(2-8) \times 10^{16}$ & $2100-2600$ & Stepanek et al $(1993)$ \\
Undoped & $p$ & $10^{17}$ & 717 & de Oliveira and de Carvalho (1995) \\
Te-doped & $n$ & $1 \times 10^{17}-5 \times 10^{19}$ & $2500-3500$ & Sestakova and Stepanek (1995) \\
Undoped & $p$ & $(1 \cdot 5-1 \cdot 7) \times 10^{17}$ & $600-750$ & Sestakova and Stepanek (1995) \\
\hline
\end{tabular}


Table 2. Hall measurements.

\begin{tabular}{lcccc}
\hline Type of dopant & $\begin{array}{c}\text { Conductivity } \\
\text { type }\end{array}$ & $\begin{array}{c}\text { Carrier con. } \\
\left(\mathrm{cm}^{-3}\right)(300 \mathrm{~K})\end{array}$ & $\begin{array}{c}\text { Hall mobility } \\
\left(\mathrm{cm}^{2} / \mathrm{Vs}\right) \\
(300 \mathrm{~K})\end{array}$ & $\begin{array}{c}\text { Resistivity } \\
\rho(\mathrm{ohm} \mathrm{cm}) \\
(300 \mathrm{~K})\end{array}$ \\
\hline Undoped GaSb & $p$ & $1.12 \times 10^{17}$ & 712.4 & 0.052 \\
Te & $n$ & $1.5 \times 10^{17}$ & 625 & 0.05 \\
In & $p$ & $1 \times 10^{17}-1 \times 10^{19}$ & 280 & 0.002 \\
\hline
\end{tabular}
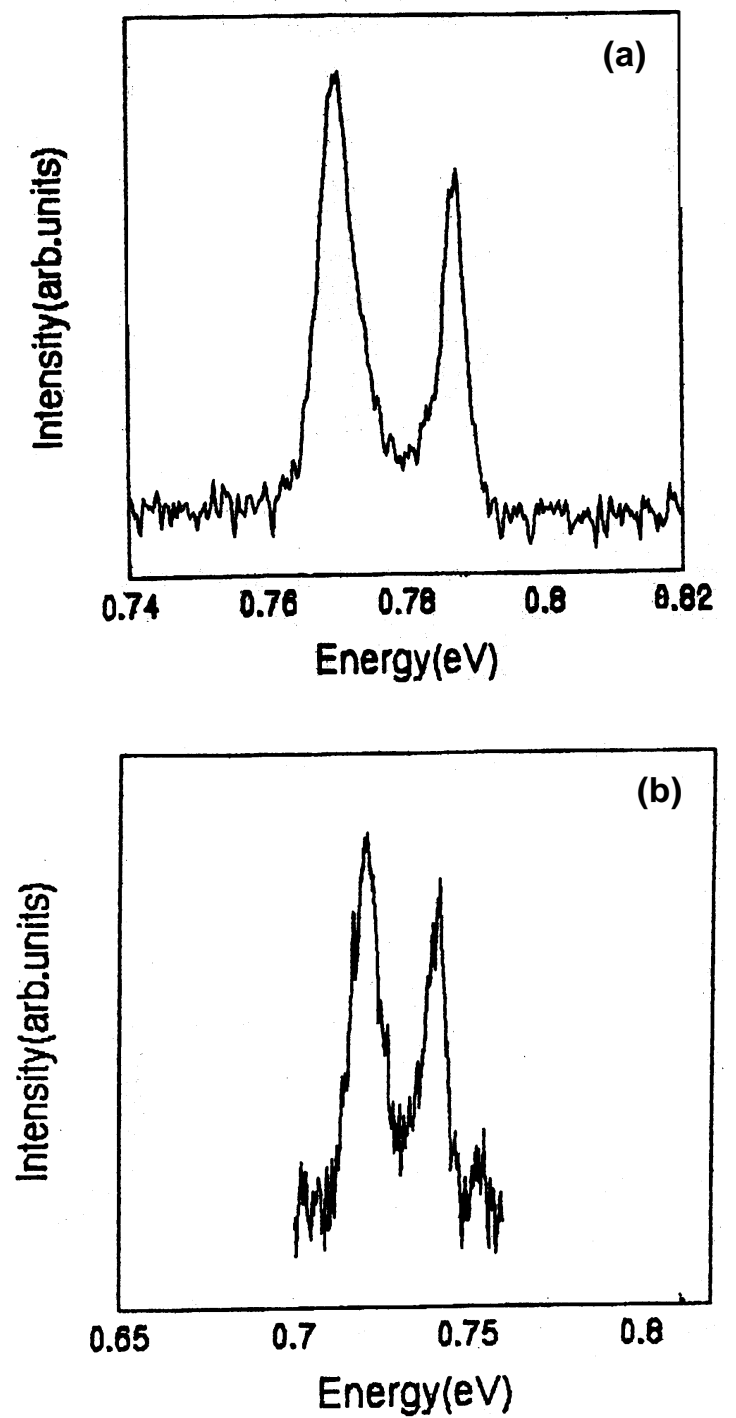

Figure 13. Photoluminescence spectra of (a) undoped GaSb and (b) Te-doped GaSb.

high-temperature pre-synthesis baking at high vacuum was carried out. This process helped to a great extent in the removal of native oxides from the bulk of the matrix which otherwise impeded the formation of homogeneous alloy. The observed structural quality of the grown ingots was much superior in terms of decreased EPD when the above procedure was adopted. In fact, a strong correlation has been observed between the structural quality of the grown ingots and the degree of mixing during the synthesis. Crystals grown with inadequate mixing showed poor structural quality and showed a large number of cracks and inclusions. The EPD values obtained for indium antimonide were $\sim 10^{4} / \mathrm{cm}^{2}$ and $\sim 10^{6} / \mathrm{cm}^{2}$ for crystals grown by horizontal and vertical Bridgman methods, respectively.

As a supplement to electrical measurements the etch pit density (EPD) for gallium antimonide was estimated. It was noticed that the EPD increased from the outer region $\left(\sim 0.9 \times 10^{5} \mathrm{~cm}^{-2}\right)$ to the core of the boule $(\sim 2.2 \times$ $\left.10^{5} \mathrm{~cm}^{2}\right)$. Harsy et al (1981) also observed higher defect density near to the core and interpreted radial heat loss to be the source of thermal stresses responsible for the formation of such dislocations. However, it is interesting to contrast this with higher EPD values observed on the outer surface of the Czochralski grown crystals (Kondo and Miyazawa 1982). In fact, a strong correlation has been observed between the structural quality of the grown ingots and the degree of mixing during the synthesis. Crystals grown with inadequate mixing showed poor structural quality and showed a large number of cracks and inclusions.

\subsection{Photoluminescence measurements}

The low temperature PL at $4 \cdot 2 \mathrm{~K}$ shows a dominant peak at $\sim 777 \mathrm{meV}$ corresponding to the neutral state of the doubly acceptor level (Swaminathan and Macrander 1991) accompanied by a transition at $792 \mathrm{meV}$ for undoped $\mathrm{GaSb}$ as can be seen from figure 13a. The PL spectrum at $4.2 \mathrm{~K}$ of Te-doped GaSb sample is shown in figure 13b. Te-related peak appeared around $740 \mathrm{meV}$. This particular transition was proposed to be from the bottom of the conduction band to the ionized state of the native acceptor (Jakowetz et al 1972). The peak corresponding to $710 \mathrm{meV}$ transition related to second ionization level of residual acceptor (Lee et al 1986) could also be observed. Significant aspect of these studies is that the transition at $\sim 792 \mathrm{meV}$ was observed which is generally a characteristic of high quality MBE grown layers (Nicholas et al 1997). The fact that the observation of this peak could be detected in the spectrum indicates high quality of the grown crystals (Dutta et al 1995). 


\section{Conclusions}

Indium antimonide and gallium antimonide were synthesized and grown by vertical and horizontal Bridgman techniques from stoichiometric melts. Preliminary characterization indicated that crystals have relatively high carrier mobilities and possessed good surface morphology. The structural quality of the crystals was assessed in terms of dislocation density and grain selection in the grown ingot. The etch pit density of the grown crystals was found to be typical of any melt-grown crystal. The effect of ampoule shape for growing good quality single crystals was discussed for vertical and horizontal Bridgman configurations. In particular, Te-doping of gallium antimonide was found to be useful for reducing acceptor density by compensation. Further, the good compositional homogeneity has been achieved by selecting suitable growth parameters. The single crystal wafers of InSb $\{110\}$ were obtained for their further use in LPE growth experiments.

\section{References}

Antonov P I, Bakholdin S I, Nosov Y G and Kalitina E S 1983 Izv. Akad. Nauk SSSR 47315

Benz K W and Muller G 1979 J. Cryst. Growth 4635

Brezina B and Fousek J 1989 Crystal growth in science and technology (eds) $\mathrm{H}$ Arend and J Hulliger (New York: Plenum) 1A p. 185

Buzynin A N, Antonov V A, Osiko V V and Tatarintsev V M 1988 Izv. Akad. Nauk SSSR 521889

Capasso F, Panish M B, Sumski S and Foy P W 1980 Appl. Phys. Lett. 36165

Cockayne B, Steward V W, Brown G T, Mac Ewan W R and Young M L 1982 J. Cryst. Growth 58267

de Oliveira C E M and de Carvalho M M G 1995 J. Cryst. Growth 1519

Dresselhaus G, Kip A F, Kittel C and Wagoner G 1955 Phys. Rev. 98556

Dutta P S, Rao K S R K, Bhat H L and Vikram Kumar 1995 Appl. Phys. A61 149

Edwards J T and Layne G S 1959 J. Opt. Soc. Am. 49414

Egan R J, Chin V W L and Tansley T L 1994 Semicond. Sci. Technol. 91591

Etter D and Etter P J 1964 J. Phys. Chem. Solids 25451

Grandsen M 1958 Electrochemical Society Meeting, New York (Unpublished work)

Harsy M, Gorog T, Lendvay E and Koltai F 1981 J. Cryst. Growth $\mathbf{5 3} 234$
Hayakawa Y, Saitou Y, Sugimoto Y and Kumagawa M $1990 \mathrm{~J}$. Electron. Mater. 19145

Heller M W and Hamerly R G 1985 J. Appl. Phys. 574626

Helmer L, Schilz J, Bahr G and Kaysser W A 1995 J. Cryst. Growth 154266

Hildebrand O, Kuebart W, Benz K W and Philkuhn M H 1981 IEEE J. Electron. QE-17 284

Hrostowski H, Morin F J, Gebalk T H and Wheatley G H 1955 Phys. Rev. 1001672

Jakowetz W, Ruhle W, Breuninger K and Pilkuhn M 1972 Phys. Status Solidi(a) 12169

Jamieson J C 1963 Science 139540

Kaiser R and Fan H Y 1965 Phys. Rev. A138 156

Keys R W 1954 Phys. Rev. 99490

Kondo S and Miyazawa S 1982 J. Cryst. Growth 5639

Kozhemyakin G N 1995 J. Cryst. Growth 149266

Lee H J and Woolley J C 1981 Can. J. Phys. 591844

Lee M, Nicholas D J, Singer K E and Hamilton B 1986 J. Appl. Phys. 592895

Milnes A G and Polyakov A Y 1993 Solid State Electron. 36 803

Moravec F 1993 J. Cryst. Growth 128457

Motosugi G and Kagawa T 1980 Jpn. J. Appl. Phys. 192303

Muller G and Neumann G 1983 J. Cryst. Growth 6358

Munekata H, Mendez E E, Iye Y and Esaki L 1986 Surf. Sci. 174449

Nagao Y, Hariu T and Shibata Y 1981 IEE Trans. Electron Devices ED28 407

Nicholas D J, Lee M, Hamilton B and Singer K E 1997 J. Cryst. Growth $\mathbf{8 1} 298$

Roy U N and Basu S 1990 Bull. Mater. Sci. 1327

Santos P V, Sood A K, Cardona M, Ploog K, Ohmori Y and Okamoto M 1988 Phys. Rev. B37 6381

Segawa K, Miki H, Otsubo M and Shirata K 1976 Electron. Lett. 12124

Sestakova V and Stepanek B 1995 J. Cryst. Growth 14687

Stepanek B and Sestakova V 1992 Thermochim. Acta 209 285

Stepanek B, Sestakova V, Hubik P, Smid V and Charvat V 1993 J. Cryst. Growth 126617

Swaminathan V and Macrander A T 1991 Material aspects of Haas and InP based structures (Englewood Cliffs, NJ: Prentice Hall) Ch. 5

van Maaren M H 1966 J. Phys. Chem. Solids 27472

van der Meulen Y J 1964 Solid State Electron. 7767

van Schilfgaarde M, Sher A and An-Ban Chen 1993 Appl. Phys. Lett. 621857

van Welzenis R G and Ridley B K 1984 Solid State Electron. 27113

Xie H, Piao J, Katz J and Wang W I 1991 J. Appl. Phys. 70 3152 